\title{
The Philosophical Foundation Of The Lecture Method Of Instruction And The Case Method Of Instruction: Implications For Examinations
}

\author{
Kavous Ardalan, Ph.D., Marist College, USA
}

\begin{abstract}
Any adequate comparison between the lecture method of instruction and the case method of instruction necessarily requires a comparison of their underlying philosophical foundation and methodology. This is based on the premise that foundational philosophies or world views underlie educational philosophies, and each educational philosophy favors a certain instructional methodology, which in turn implies a certain way or method of instruction. More specifically, this paper discusses how each philosophical foundation implies a certain type of examination.
\end{abstract}

Keywords: Case Method of Instruction; Lecture Method of Instruction; Educational Foundational Philosophy

\section{INTRODUCTION}

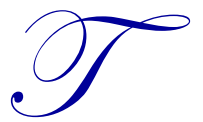

his paper crosses three existing lines of literature: foundational philosophies, educational philosophies, and educational methods. To implement this aim, the paper has benefited from the existing literature cited in the reference section. The aim of this paper is not so much to create a new piece of puzzle as it is to fit the existing pieces of puzzle in order to make sense of it.

Based on Burrell and Morgan (1979), Ardalan (2008) discusses how each educational philosophy can be related to one of the four broad worldviews or paradigms: functionalist, interpretive, radical humanist, and radical structuralist. The four paradigms are founded upon mutually exclusive views of the social world. Each generates educational philosophies, instructional methodologies, ways or methods of instructions, theories, concepts, and analytical tools which are different from those of other paradigms. More specifically, the functionalist paradigm underlies educational realism; and the interpretive paradigm underlies educational pragmatism. In turn, educational realism underlies the lecture method; and educational realism underlies the case method. In the next section, this paper discusses how each of these educational methods underlies a specific type of examination.

\section{IMPLICATIONS FOR EXAMINATIONS}

This section discusses how the sequence of foundational philosophy, educational philosophy, and educational methodology leads to a specific type of examination. In order to show this, the section focuses on certain aspects of the lecture and case methods of instruction and compares them. Since most readers are familiar with the lecture method, the discussion in this section elaborates more on the case method.

\section{II.A. Textbook vs. Cases}

The lecture method requires textbooks, whereas the case method uses descriptions of specific business situations. In the lecture method, the educational goal is for students to learn textbooks facts. However, students may forget those facts as soon as they graduate. In the case method, the educational goal is to instill in students practical knowledge and, more importantly, to provide the opportunity for them to develop the skill of logical and correct 
reasoning in every subject. In the lecture method, the use of textbooks leads students to believe that whenever they apply the techniques stated in the textbook they will be able to solve real-world problems. In the case method, teachers believe that textbook techniques may not work since the practical world is much more complex. In the lecture method, teachers use textbooks. They do not explicitly teach the conceptual framework of their subject matter, but they teach the textbook techniques. In the case method, teachers' concerns are for the students to understand and be able to apply the conceptual framework of their subject matter and, therefore, teachers consistently use that framework. They do this because a business manager is far more involved with the conceptual framework of the subject matter than with its techniques. In the case method, teachers arrange a sequence of experiences involving students. Then, teachers use their knowledge of the conceptual framework to ask questions and call on students for reactions. In this way, students gradually acquire a working capacity to deal with the fundamental concepts. In the lecture method, teachers follow the textbook outline and hope that the students will somehow obtain a working understanding of what the teacher teaches. In the case method, the emphasis is on relating analysis and action. While the lecture method's emphasis is to know, the practitioner's necessity is to act. The case method combines these two activities. The manager's primary task is the application of knowledge, which is partial to the complexities of administrative problems and does not produce complete solutions. In the case method, the emphasis is on situational analysis. It shows the vast gap which exists between global prescriptions of the lecture method and what a specific manager needs, at a specific time, with respect to a specific problem. The case method helps students to develop the capacity to deal with specific situations, which is in contrast to the lecture method's emphasis on the provision of generalized statements. In the case method, students gather experience in many case discussions and derive generalization, which are stated tentatively, tested frequently, and used carefully. In the case method, it is believed that logic and mathematics do not exhaust the nature of reality and therefore it is not believed that if students only read one more textbook they would have the solutions to problems. In the lecture method, it is believed that the solutions to human problems are found in logical statements and propositions and therefore students' formal education is primarily intellectual, i.e., they learn abstract concepts, general propositions, and answers.

\section{II.B. Single Answer vs. Multiple Answers}

In the lecture method, the educational process is devoted to applying rigorously-defined methods to questions or problems carefully posed by others in order to find answers. In the case method, students learn a generalized approach to problem-solving or decision-making which involves not only the application of analytical techniques for choice-making, but also identification of problems and recommendation of solutions. In the case method, education is regarded as a process of drawing out the student's mind. In the lecture method, education is regarded as transferring teacher's ideas and textbook contents to the student's mind. In the case method, value is given not in what students dig out, but in what they gain by digging. In the case method, students are expected to find things out for themselves because there are no answers in the back of the book, and in most cases there are no books at all. In the lecture method, teachers tell students. In the case method, teachers expect students to study the case and then tell teachers, and then teachers ask questions from students while probing, challenging, and insisting on respecting facts, logic, and consistency. In this way teachers help students to sort out the relevant facts, define the problems, formulate critical questions, evaluate answers to those questions by weighing evidence and pros and cons, and decide as if they were in charge. In the case method, students are involved in class discussion of possibilities, probabilities, and expedients: the possibilities of the combination of very intricate facts, the probabilities of human reactions, and the expedients most likely to bring about the responses in others that lead to a definite end. The purpose of business education is not to teach truths (if there are such things as truths, as the lecture method claims the existence of truth) but to teach students to think and decide when they face new situations. Indeed, there is rarely a single case with at least two intelligent solutions. In the case method, multidimensionality is one of the major aspects of cases and students look at everything simultaneously and talk about anything that needs to be changed, improved, or modified. Although the case provides the students and the teacher with the same amount of information for their decision making, they voice different opinions and suggest different solutions. A lecture teacher prepares an analysis of the case from a scientific point of view that is totally exhaustive, mutually exclusive, and gives a clear breakdown, ensures the class gets there, and forces the students into his/her assumptions and framework. A case teacher not only prepares the case content but also sets his/her class plan in terms of the behavioral, conceptual, and analytical teaching objectives. In the case method, differences of opinion are the norm. Usually, there are more than just one single acceptable answer to a complex business situation. In a case discussion, 
most aspects of the case are discussed and each student is exposed to other viewpoints. The teacher may test the consensus on a controversial point by having a show-of-hands vote. The teacher and the students acknowledge that the minority may be right. In the case method, learning flourishes when it is anchored in a climate of genuine respect, trust, and openness to diversity. In case discussions, students note that, as human beings, they usually see only what they want to see or what they are accustomed to seeing. At the end of the case discussion a consensus about the best alternative or decision may not emerge, because more than one alternative may be fully reasonable. The lecture method is very powerful in the transfer of knowledge from the teacher to the students. The case method is very powerful in promoting critical thinking (in the liberal arts setting), problem-solving (in the professional school setting), sensitivity, cooperation, and desire for discovery. In the case method, students see in partnership both the teaching/learning process and their own selves. Students take responsibility of their own education by deepening their personal involvement, participating in quality discussion, and making an emotional investment in the outcome of the course. This responsibility not only stimulates them to develop, but also enhances the effectiveness of the teachers. In discussing cases, diversity in backgrounds, personalities, questions posed, learning styles, frames of inquiry, and spectrums of interpretation ensures that the class does not search for the only path to the only answer. In this way, the powerful energy of experience and creativity of students will be unleashed.

\section{II.C. Rigidity vs. Flexibility}

In the case method, teachers help students to explore unfamiliar situations, to experience decision-making under uncertainty, and to practice the art and science of management, or other professions. In the case method, students learn to accept compromise and accommodation. In the lecture method, students learn to search for the perfect solution. In the case method, students learn to view action as a spectrum of potential possibilities. In the lecture method, students learn to view action as a few go or no-go intervention points. In the case method, students learn that almost all management challenges are based in the human and organizational context. Technical, financial, or conceptual issues are closely related to people in the action stage. The issues can be dealt with only when the human issues are simultaneously dealt with as well. In the case method, a major section of the case explains the background of the organization and the industry. This section defines the context for the problem. Normally, there are several alternatives for making a decision and the preferred one depends on circumstances. This is because no standard universal solution exists. A similar practice is followed in medicine. Different people with headache cannot be cured by prescribing one particular medicine. The doctor's analytical skills distinguish among treatment options by looking at the patient's personal health, age, economic, social, and cultural factors. In the lecture method, teachers organize their courses with an overall framework regarding a manager who in dealing with a particular topic has to think about, has to worry about, and how they are related to each other and to other areas in the business. In the case method, teachers believe that most areas of business are not that clear-cut. That is, the world is so complex that denies one global solution. Similar to psychologists and sociologists, they do not use one overall framework, but many frameworks. Teachers set priorities for their courses. This is because class time is a scarce resource and more important topics receive preference over others. In both the lecture method and the case method, priority is given to students' understanding of certain concepts. In the case method, teachers review course objectives, case objectives, plans for a particular class within all classes, and the importance of having a particular class and a particular case within a particular course. In addition, in the case method, priority is given to distinguishing relevant information, proper application of relevant theory to practice, problem identification and analysis, alternative generation, decision-making, and implementation planning. In the first few classes, priority is given to familiarizing students with the discussion process and the teacher's expectations regarding student preparation and participation in class. In the case method, therefore, priorities are multidimensional, i.e., they are both process and content oriented. In the case method, teachers provide the necessary services which group discussions require. They keep discussions orderly. They ask questions which are related to the ongoing discussion and enhance group thinking. They combine individual contributions into a pattern which their class can understand. They manage class time in order to avoid a discussion which is either too slow and is not utilizing well the available time, or too fast and is not allowing enough comprehension on the part of a major portion of students. They have control over the undirected class discussion, but at the same time allow the class to make its discoveries, which may be new even to the teachers. Since unpredictable developments are the hallmark of real learning, teachers examine their class rather than their subject matter. In the lecture method, teachers can prepare a good lecture in a few hours and have control over the order and timing of what is to occur. Teachers include humor to keep students interested. Teachers know when to add something unusual to get the attention of a student whose mind is not in the class. 
Teachers anticipate most of students' questions and prepare the answers beforehand and maintain their self-respect in view of the students' questions. In the case method, teachers spend a lot of time on their case preparation. This is because they want to be prepared to go wherever the discussion goes. That is, teachers are not in control because the vehicle is the students' vehicle. It is much more difficult to influence the process of the case discussion productively. In the case method, students who transfer from or come with a background in sciences face difficulty. This is because they have been trained and conditioned into rigidity, which is the norm in the lecture method. In contrast, in the case method, it is learning to become non-rigid. In the case method, students analyze, evaluate, and compare alternatives by following the standard approach of listing the key advantages and disadvantages of each alternative. Then, they weigh these pros and cons to select the best course of action. They compare and contrast each alternative, in light of the decision criteria they have selected, in order to make the best decision, which can be quite challenging. When they have selected multiple decision criteria, they decide based on the weighting of each criterion against the others. For instance, in most cases, there are concerns about the short and the long term. Both short- and long-term considerations are relevant in analyzing alternatives, predicting corresponding outcomes, and planning and implementing action. The alternatives may be as follows: (1) One with quick and highly beneficial results but average long-term consequences, or (2) Another with good long-term prospects but average immediate pay-offs. Students decide with respect to the actions which need to be taken in both the short term and the long term. Indeed, the frequent exercise of judgment based on the case situation and students' experience makes learning in the case method so unique. In the case method, students learn through the group discussion process. In practice, the final decisions regarding business problems are reached only after discussions take place among smaller and larger groups. Each case class is both a group discussion in arriving at a business decision and a practical experience in group's behavior. Each case class provides an opportunity to listen to the views of others and to express and persuade others to one's point of view. It provides an opportunity to gain confidence in one's own judgment, while become humiliated some of the times. It shows to what limited extent one can move forward through the rigorous logical analysis of one or another dimension of the problem (which is the teaching of the lecture method) and to what extent judgment comes into play when many diverse factors must be weighed.

\section{II.D. Certainty vs. Ambiguity}

The lecture method is efficient and economical in the use of time, energy, and the patience of instructor and students. Students seem to possess sureness, precision, and grasp of materials which is remarkable for the relatively short time they spend on acquiring their knowledge. The case method trains students to act, rather than training them to know. This is because businesspeople must be able to act in the face of problems arising in new situations in a continually-changing environment. That is, education consists of acquiring skills necessary to act in new situations. In the lecture method, students are trained under more structure. This makes it easier for them to go through the course but not an easier way to learn. Such students become frustrated when they move from the lecture method to the case method. This is because the case method brings more realism to the classroom. In the case method, students learn to tolerate incompleteness of information and ambiguity of situations. They learn how to face multidimensional issues and formulate action plans. They learn to recognize what the problem is in order to select the appropriate tool. The students who come into the case method from a lecture method background, most often face difficulty in making such recognition. This must be because they are trained to be too much involved in the technical details of problems. In the case method, on the other hand, students learn to develop a disciplined mental approach to an unstructured problem. Students are trained in such a way that they are able to make decisions in practical business situations. Therefore, students are not expected to go through unnecessary detailed numerical calculations, which is in contrast to the lecture method. In the case method, starting with the first course, students face uncertainty, difficulty, complexity, which they have to make some order out of it. According to the problem-solving framework, the teacher may decide not to distribute the course syllabus, but rather talk about it. That is, the teacher may decide not to present the course and then implement, but rather expect students to derive the course concepts and the course framework from the discussion. The students might not know where the class is leading to until the class actually implements it, which is an exercise in making sense of uncertainty. The teacher may distribute the course syllabus in the class close to the end of the course and explain what the class has done, what cases have been used, what the class has done with respect to those cases, and where the class has reached. That is, after the fact, the teacher describes what the course was. Indeed, the teacher describes what the students have learned and how they have learned it and the students realize what they have been doing after they have done it. In the case method, students experience considerable confusion, frustration, and anxiety. This is because cases can be long and complex, 
with or without assigned questions, and with or without right answers. Moreover, cases are open-ended and may provide limited or overwhelming amount of information. Furthermore, students have limited experience with the issue, industry, or product at stake. In the case method, usually cases provide limited information which requires students to make assumptions. This reflects real business situations in which managers do not possess all the information they need, or are not able to acquire it, before making decisions. Frequently, managers are forced to make decisions based on partial information and, of necessity, make assumptions. Students analyze cases based on the information available in the case and can use their own background and experience to provide the political, economical, social, and technological context of the case. Most often, students recognize that they do not have enough information to assess the situation and experience the need to make assumptions. The case method provides students with ample opportunity to develop their skills in making sound assumptions, which is a delicate matter. Students should be aware when they are making an assumption. The assumptions should be plausible and realistic in the light of the information provided in the case. That is, students need to make sensible inferences tied to known facts. They should be able to justify it and explain the rationale behind it by reference to the evidence, knowledge, or experience which they base it on. Students should be cognizant of hidden assumptions, which are made implicitly or without awareness. In the case method, it is almost always necessary to make some assumptions due to the lack of sufficient information. Consequently, assumptions become an integral part of any case analysis and action plan. Students may disagree on their assumptions. Teachers spend some time in class to make sure that the case analysis and alternatives are based on reasonable assumptions, given the case circumstances. In the case method, students are expected to be explicit about their assumptions. Most often they make different assumptions, which is not necessarily a cause for concern. The role of assumptions becomes prominent when different assumptions lead to differing decisions. In case discussions, student experience some initial confusion, some initial wrestling, but the decision-making is critical. When students differ on the critical components, they should talk about their differences. In the case method, teachers usually instruct the group that will formally present the case to distribute a list of its assumptions one class meeting before the presentation. Each student uses these assumptions, together with facts given in the case, to prepare for the discussion of the case in class. Given the same set of premises, the focus in this phase of class discussion is on the use of sound logic, which examines inferential reasoning. In another phase of class discussion, priority is given to an in-depth examination of the distributed assumptions. The discussion focuses on whether each assumption is necessary and whether it is sufficiently reasonable given the circumstances in the case. All cases are culture bound and given the right set of assumptions, each point of view holds a certain amount of truth. In the case method, there are uncertainties for the teacher as well, which is in contrast to the lecture method. Class meetings do not follow a standard process or procedure. Teachers focus on managing the participative process and reinforce process variability from the start. Teachers manage the discussion process with a reference base from which variations can be contrasted. Variation may depend on the objectives of the class, the type of case, the place of this class in the sequence of classes, what happened in previous classes, other classes in other courses which are taken simultaneously by the students, the teaching style and mood of the instructor, the mood of the students, the time of year, the weather, the political and economic news, and so on. Teaching with cases is hard for teachers who prefer to imitate a standard objective model but delightful for innovative teachers. In the case method, every class involves the opportunity for new intellectual adventure, risk taking, and new learning. The teacher might have discussed the case in previous courses, but previous teaching notes have limited current value. This is because with a new group of students there will be a unique class dynamic under different time circumstances with new questions.

\section{II.E. Objective Exams vs. Combined Objective and Subjective Exams}

In the lecture method, teaching is telling, knowledge is facts, and learning is recall. Teachers deliver content in the form of factual information and students receive it. Learning is satisfactorily completed when the student successfully transfers the material back to the teacher at the specified time. In the lecture method, distinction among students is based on objective criteria because of its emphasis on factual information. Those students who understand the materials at some minimally-acceptable level will succeed and those who do not will fail. The assessment tools include true-false questions, multiple-choice questions, objective exercises, and objective exams. In the lecture method, students study by themselves and take examinations. In the case method, as in the business world, the ability to communicate with others is considered far more important than the ability to write a good examination. In the case method, the focus is on the development of analytical and decision-making skills. In the lecture method, the focus is on the acquisition of knowledge in the form of management theories and techniques. Of course, acquiring such knowledge is important, but its acquisition is likely to be more effective through lectures or 
readings. In the case method, assignments are used as a vehicle to bridge instructor case analysis and student case analysis and to bridge instructor expectations for learning and student class discussion progress. Students are encouraged to go beyond the assigned questions when preparing their case analysis because it is a useful problemsolving skill with high pay-offs. In the case method, cases reflect reality, with all of its deceptions, contradictions, discrepancies of perception, and general resistance to orderly analysis. Cases have a core of ambiguity which generates a great deal of energy and liveliness in class discussions. Cases are controversial and study questions are open-ended, which frequently involve judgment. They help students clarify their own and each other's hidden assumptions. Cases encourage students to improve and defend their positions. Cases lure biases into the light for examination and assessment and avoid complacency. In the case method, teachers do not offer students a code of rules or techniques. Each case is a slice of real life and the lessons it suggests varies for each student. In the case method, complexity and uncertainty are dealt with, but not by applying specialized knowledge of well-defined tasks. That is, artistry is not reducible to the exercise of known routines. Similarly, problem finding does not belong to a body of knowledge concerned exclusively with problem solving. Among competing paradigms of professional practice, one cannot rely on professional expertise. The competencies central to professional practice are separate from their underlying model of professional knowledge. In the case method, students who graduate are aware that their education has not provided them with a body of specific knowledge, a set of formulae and answers, and readymade patterns of behavior that enables them immediately to become successful administrators. They are aware that this is the norm under the lecture method. In the case method, students develop skills to analyze a situation, to formulate a plan of action, and to implement it through the people in their organization or in their community. Students trained with the case method are aware that business problems do not have one easy, simple, right method of analysis which leads to only one correct answer, as in the lecture method. They are aware that companies hire at an average pay level many average-grade technicians who can calculate the right answers to the problems that lend themselves to exact routines and procedures. They are aware that companies pay a very high price for qualities of judgment and leadership ant that they cannot develop those qualities if they look for easy answers and oversimplify the world they live in, as in the lecture method.

\section{II.F. Objective Grading vs. Combined Objective and Subjective Grading}

In the lecture method, teachers develop grading schemes with specific grades for every step taken. In the case method, teachers do not adhere to such grading schemes. They would like to know if the student makes sense and how well the case discussion is developed. If the student does not make sense, then no amount of individual points makes the whole discussion acceptable. In the case method, student evaluation is much more difficult because of the lack of any precise grading scheme against which to measure the student's performance. The measurement of the student performance vis-a-vis the teacher's objective is extremely subjective. It is one of the risks that both the teacher and students take. In the lecture method, the teacher enters students' answers into a computer and they will be graded as right or wrong, and the teacher has a very precise numerical grade for each student. In the case method, most cases do not have right or wrong answers. The quality of students' case analysis depends largely on their decision-making skills. It is their ability to distinguish the important from the urgent, the short term from the long term, the immediate from the basic, and the preferred from the less desirable which shows their insight that creates the power of persuasion that produces superior grades. In the case method, students' grades are determined based on objective and subjective criteria. For instance, in their case analysis, students should identify their key assumptions by reference to the information provided in the case, knowing that different sets of sound assumptions are made by different students on the basis of the same case information. Moreover, students should demonstrate that the correct method is used when an analytical tool is applied. Furthermore, students should demonstrate that their arguments for or against any alternative solution are consistent not only with their assumptions and calculations but also with the prior interpretations of the case information. In the case method, for instance, if there are 10 points allocated for a recommendation, the teacher may assign a grade between 7 and 10, depending on how the student's paper impresses the teacher. In this way, the teacher reduces some of the subjectivity in grading by specifying numbers. In the case method, teachers create their grading scheme by first developing a framework of what they expect based on what they consider important. Then, they read several students' papers to recognize their analytical framework in order to develop a grading scheme. For example, the final grading scheme states that the implementation is worth 10 points: Idea $\mathrm{X}$ is worth 2 points, and idea $\mathrm{b}$ is worth 2 points, etc. such that all add up to 10 . Teachers make a subjective evaluation of students' handling of the implementation with some reference to the list of ideas. In the case method, in contrast to the lecture method, grading is both objective and subjective. Despite teachers' efforts to develop 
grading scheme, much of the grading remains subjective. For example: (1) Some teachers allows students to select the weights for different components of evaluation. This gives students an opportunity to exploit their strengths, balance project workloads, etc. (2) Most teachers who believe in the discussion/involvement format and the students' contribution to each other's learning argue for grading participation, which is very subjective. (3) Most teachers' grades are curved, which represents the teacher's expectation of a typical student achievement. Different teachers have different shapes for the curve in mind. The grade distributions at grade conference time at the end of the term show how different teachers' curves can be. In the case method, teachers use a student peer evaluation system for their group work. They ask students to assign anonymously a letter grade to each of their group peers. Teachers list for them the criteria which they have to consider in assessing their peer contributions to the group. Then, teachers incorporate the individual aggregate score in making grade decision. In the case method, teachers assign participation grades to students. At the end of every class meeting they go through the class list. They determine whether the student participated, and decide on the quality of the discussion of those who participated. The teachers do this even though they know it is not overly scientific. Then, at the end of the course, they add up the quantities and rank students. Then they look at each individual student and readjust this ranking by whether they feel a student has fewer entries, but those few are of high quality. The teachers' final decision is a subjective one. They ask how good the student is. The teachers may not allow participation grades to fail a student. However, they may allow it to drop the student's grade. If a student had outstanding participation and one bad examination, the teachers may reduce the weight of that examination. It seems that the teachers are scientific by grading students after each class, but at the end of the course it is their subjectivity which determines the course grade.

\section{CONCLUSION}

This paper showed how foundational philosophies or worldviews underlie educational philosophies, and each educational philosophy favors a certain instructional methodology, which in turn implies a certain way or method of instruction. More specifically, this paper showed how each foundational philosophy implies a specific type of examination. The paper emphasized that there is no unique evaluative perspective for assessing instructional methods generated by different foundational philosophies. Therefore, it becomes necessary to get beyond the idea that instructional methods can be evaluated in an absolute way.

\section{AUTHOR INFORMATION}

Kavous Ardalan is a professor of finance at Marist College. He holds Ph.D.s in Economics and Finance. Since 2000, he has been a top-ranked author in finance and economic education. His research interests are in the theoretical, practical, educational, and philosophical aspects of Finance. Of his research papers, four have received awards at conferences; two have been recognized very highly by the publishers; and three have been referenced in the "Handbook of Finance". His book is entitled "On the Role of Paradigms in Finance". Kavous Ardalan owes much to his wife (Haleh), their son (Arash), and their daughter (Camellia). E-mail: Kavous.Ardalan@Marist.edu

\section{REFERENCES}

1. Ardalan, Kavous, 2008, "The Philosophical Foundation of the Lecture-versus-Case Controversy: Its Implications for Course Goals, Objectives, and Contents," International Journal of Social Economics, 35(1/2), 15-34.

2. Barnes, Louis B., Abby J. Hansen, and C. Roland Christensen, 1994, Teaching and the Case Method: Text, Cases, and Readings, Harvard Business School, Boston, Massachusetts.

3. Burrell, Gibson, and Gareth Morgan, 1979, Sociological Paradigms and Organizational Analysis, Gower Publishing Company Limited, Hants, England.

4. Christensen, C. Roland, and David A. Garvin, 1991, Education for Judgment, (eds.), Harvard Business School Press.

5. Erskine, James A., Michiel R. Leenders, and Louise A. Mauffette-Leenders, 2003, Teaching with Cases, Third Edition, London, Ontario, Canada: Ivey Business School, University of Western Ontario, Erskine Associate Inc, and Leenders and Associates Inc.

6. Mauffette-Leenders, Louise A., James A. Erskine, and Michiel R. Leenders, 2007, Learning with Cases, Fourth Edition, London, Ontario, Canada: Ivey Publishing, Ivey Business School, University of Western Ontario. 


\section{NOTES}

